\title{
Prospects for a Development of a High-Tech Production of Competitive Science-Intensive Electrical Products
}

\author{
Albert Rafisovich Gallyamov ${ }^{1}$, Pavel Viktorovich Rogojin ${ }^{1}$, Sergei Urevich Ganigin ${ }^{1}$ \& Ildar Duglasovich \\ Ibatullin ${ }^{1}$ \\ ${ }^{1}$ Samara State Technical University, Russia \\ Correspondence: Albert Rafisovich Gallyamov, Samara State Technical University, Russia.
}

Received: October 30, 2014

Accepted: November 6, $2014 \quad$ Online Published: January 11, 2015

doi:10.5539/mas.v9n4p106

URL: http://dx.doi.org/10.5539/mas.v9n4p106

\begin{abstract}
The presented paper discusses a technology of a production of aluminum substrate - copper sublayer - silver coating combined layers, which is developed for a replacement of copper electrical contact elements, used in integrated switchgear, for aluminum ones The comparative analysis of existing technologies of formation of a copper intermediate layer was carried out. The substantiation of a choice of non-stationary modes of an electric current and perspectivity of their application for galvanic sedimentation of a protective current-carrying covering of silver was resulted. Quality of the received combined covering copper-silver on pre-production models of electric contacts was investigated.
\end{abstract}

Keywords: current distributor, electrical properties, copper sublayer, surface films, silver-diamond coating

\section{Introduction}

Among heavy duty friction assemblies, ones that take a special place are connections with electrical load in high-power electrical units, where, apart from high mechanical stress, there is large current load. The essential elements of high-voltage and high-current electrical equipment are current distributors and electrical contacts. Manufacturers of electrical products have a need to reduce material consumption and cost of products. That possibility appears in a case of using cheaper and more accessible materials, while maintaining required wear properties of contact pairs. In electrical power engineering, main electricity conductive materials are copper and aluminum. The cost of copper is 4 times more than the cost of aluminum; however, electrical conductivity of copper is one and a half times greater than electrical conductivity of aluminum. Another advantage of aluminum is that it is lightweight metal (aluminum density is 3.31 times density less than copper density). In an existing engineering designs of buslines and current distributors, a possibility exists for a replacement of copper products for aluminum ones without a loss of electrical and tribotechnical performance. The special feature of such contacts is a presence of transition conductive zones with high wear resistance (in particular, resistant to abrasion). A formation of a transition zone on aluminum contact surfaces is a topical scientific and technical problem. An achievement of required adhesion performance in aluminum-copper-silver transition zone, which was at the same level as adhesion of galvanic silver coating on a copper part (adhesion of silver on copper substrate reaches $160 \mathrm{MPa}$ ), using generally accepted methods is impossible. An application of copper sublayer on aluminum using electrochemical plating method is obstructed by strong oxide film on its surface, which is preventing a satisfactory adhesion of deposited coating (Lukomski and Gorshkov, 1985). Another important reason, which hinders an application of electrochemical coatings on aluminum, is a high negative value of aluminum's potential and its tendency to a transition in ionic state. That process causes contact displacement from electrolyte solutions of more electropositive, as compared to aluminum, metals: zinc, copper, silver, nickel, tin, chromium, etc.

\section{Methodology}

In the laboratory of SamSTU a high performance technology of an application of silver-diamond coatings on aluminum contacts is under development, which comprises pre-processing of substrate by means of detonation method based application of copper sublayer (Figure 1). 


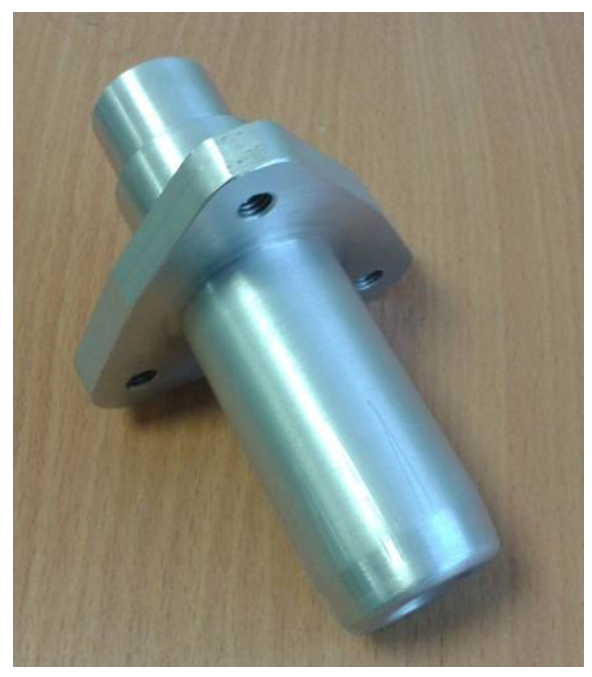

a

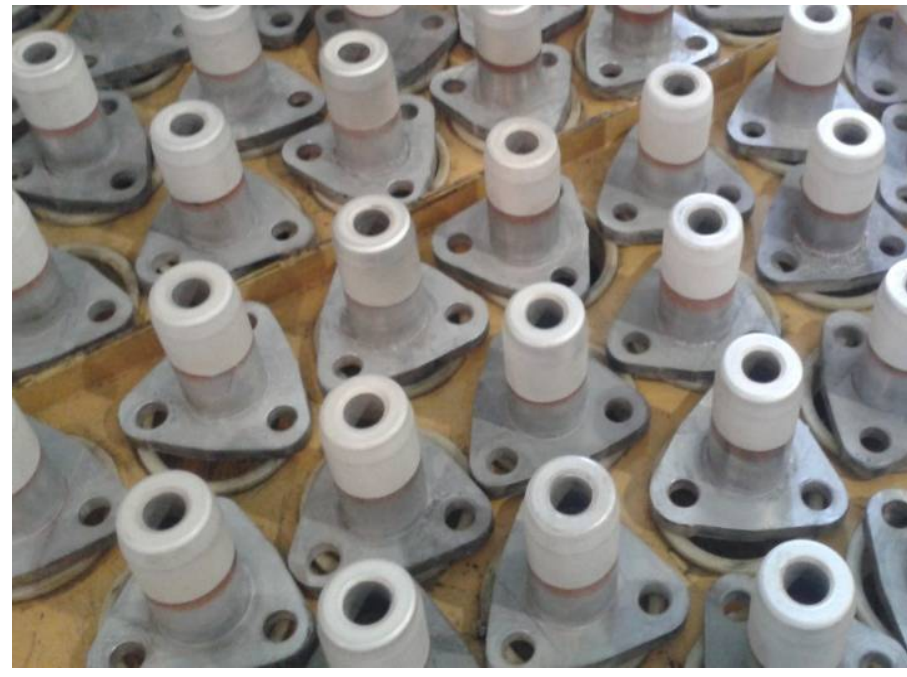

b

Figure 1. Contact part (SESha-70) of "Tul'pan [Tulip]" type: (a) contact-part without coating; (b) contact part after an application of a copper sublayer and silver-diamond coating

Nowadays, for a formation of coatings with high mechanical bonding the most widely used methods are gas-thermal methods, including, gas-flame, plasma and combustion methods of coatings' application. Generally, those methods consists of a deposition of functional powder materials (PM) in a special equipment by means of electric heating of PM or diesel combustion with a simultaneous acceleration in a jet of compressed air. At the same time, as it shown in the works (Hasui, 1988; Sova, et al., 2009; Bartenev, et al., 1982; Yu, et al., 2003; Gavrilenko, et al., 2006; Ul'yanitzki, et al., 2010; Kadyrov, \& Ladan, 2002), the best technical characteristics of coatings (maximum strength and adhesion to substrates, minimum porosity and gas permeability) are provided by detonation method. Table 1 shows the comparative results of an application of various methods of a deposition on parts (Kadyrov, et al., 1996).

Table 1. Comparative parameters of different methods of gas-thermal coatings' application

\begin{tabular}{|c|c|c|c|c|c|}
\hline $\begin{array}{c}\text { Method } \\
\text { of deposition }\end{array}$ & $\begin{array}{c}\text { Temperature } \\
\text { of gas mixture, } \\
{ }^{0} \mathrm{C}\end{array}$ & $\begin{array}{c}\text { Temperature } \\
\text { of a part, } \\
{ }^{0} \mathrm{C}\end{array}$ & $\begin{array}{c}\text { Speed } \\
\text { of powder, } \\
\mathrm{m} / \mathrm{sec}\end{array}$ & $\begin{array}{c}\text { Porosity } \\
\text { of coating, } \\
(\%)\end{array}$ & $\begin{array}{c}\text { Adhesion } \\
\text { of coating, } \\
(\mathrm{MPa}) \text {. }\end{array}$ \\
\hline Detonation & 3500 & 150 & 1200 & $0,1-1,0$ & $80-120^{*}$ \\
\hline HVOF & $2500-3100$ & 1000 & $500-800$ & $1-10$ & $83 *$ \\
\hline Plasma & $5500-15000$ & 1800 & $200-800$ & $1-10$ & $55-69 *$ \\
\hline $\begin{array}{l}\text { Electric arc } \\
\text { metallization }\end{array}$ & $4000-6000$ & 1000 & 240 & $10-20$ & - \\
\hline Gas-flame & $2500-3000$ & 1500 & $30-180$ & $10-30$ & $30-40$ \\
\hline
\end{tabular}

From the data in the table 1 it is clear that the process requires a minimum warm-up of a processed part, which reduces a possibility deformation-related mechanical changes and residual mechanical stresses in it.

Detonation method of application of coatings is based on a high-speed projection of sprayed powdery material by detonation products of gas mixture. Detonating gas mixture and powder, which is distributed in the gas mixture, are fed into channel of nozzle. Spark discharger initiates the gas mixture. In an explosion chamber combustion transits into detonation stage. Detonation wave speeds up powder up to $400 \ldots 1200 \mathrm{~m} / \mathrm{s}$ speed. Particles, carried by detonation products to a surface of a substrate, collide with it, forming coating of $3 \ldots 15$ micron thickness. Nozzle and gases mixing chamber are purged with nitrogen in order to remove detonation products. After that they filled with a new portion of an explosive mixture and the cycle is repeated. Depending on a design of equipment, cycle frequency can be up to $8 \ldots 10 \mathrm{~Hz}$, but in the most cases it is equal to $3 \ldots 4 \mathrm{~Hz}$ (Gavrilenko T.P. et al., 2006). High temperature and speed characteristics provide an opportunity for an application of coating with high hardness, wear resistance, substrate adhesion strength (adhesion 80-250 MPa) in 
combination with low porosity values $(0.5-1 \%)$, which makes detonation method competitive and in some cases indispensable for strengthening parts of machines and mechanisms (Ul'yanitzki, et al. , 2007).

The process of coatings formation is characterized by a large number of factors, the main of which are as follows: chemical composition and physical properties of powder particles' material and substrate material; composition of detonating gas mixture; depth of powder loading (a distance from an input of powder before to an end of nozzle); distance of a deposition; particles state of matter before an interaction with a substrate; concentration of melted particles; speed and dispersion of particles; substrate surface geometry; chemical composition of a substrate's environment; particles temperature and substrate surface temperature before a deposition; concentration of particles in different parts of a two-phase stream and others.

At that, following variants of a surface's preparation and intermediate layers' formation are used: formation of copper sublayer by gas-dynamic method and detonation method; preparation of copper sublayer with grinding and without it; heat treatment of copper sublayer; formation of copper sublayer by gas-dynamic method and detonation method; increase in aluminum's surface roughness before an application of coating by mechanical method - sandblasting, hydroabrasive processing or chemical method - etching in hydrochloric acid and hydrofluoric acid; pin method intermediate films deposition of an auxiliary metal; electrochemical deposition of coatings on aluminum.

In order to confirm adequacy of theoretical assumptions, a formation of a copper coating by detonation method on a surface of aluminum contact element of "Tul'pan [Tulip]" type are conducted. Before an application of copper coating, the surface was subjected to abrasive-jet treatment in order to clean it and to provide conditions for adhesion with a surface of aluminum contact. For an application of detonation coating detonation deposition equipment (Figure 2, a) with a control software was used, which provides specified uniformity of coating during an application of several of consecutive layers with spiral application pattern.

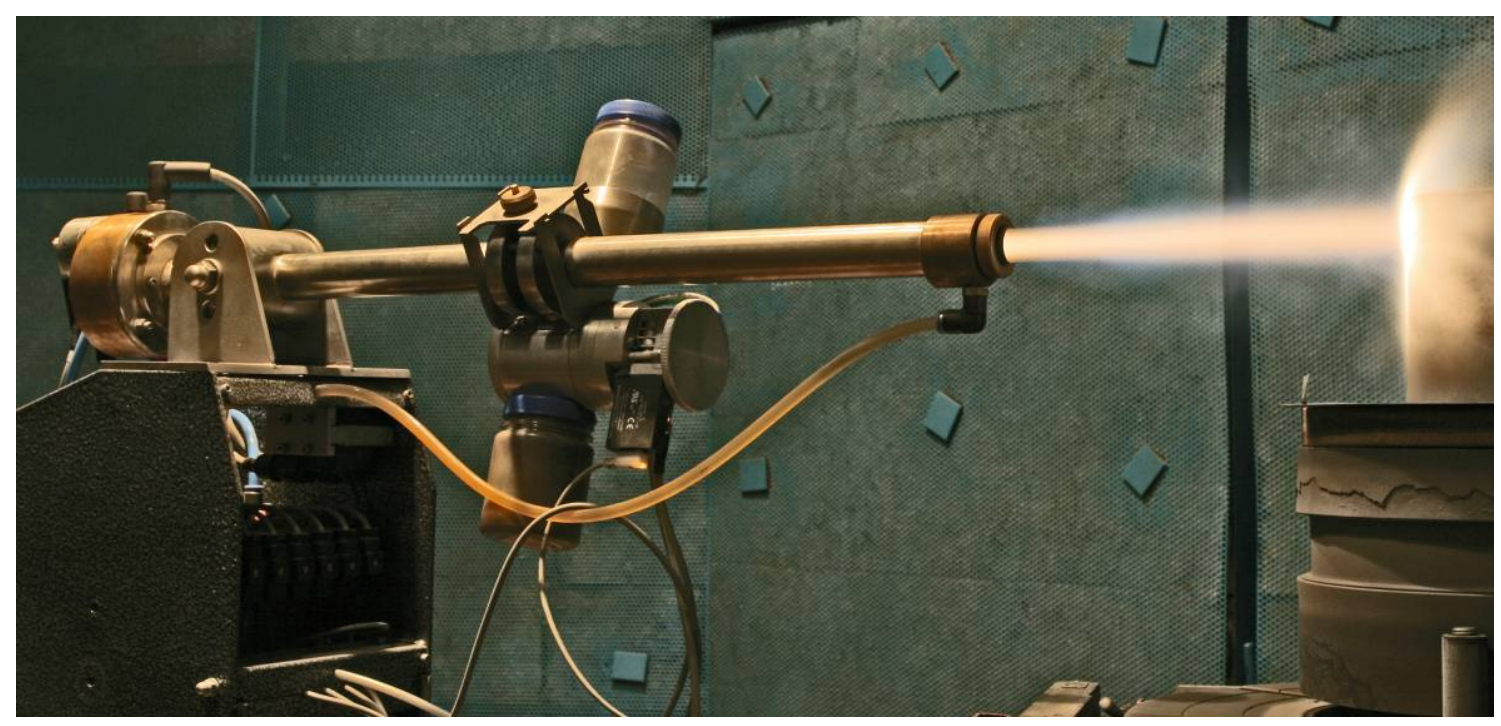

Figure 2. Equipment for detonation deposition 


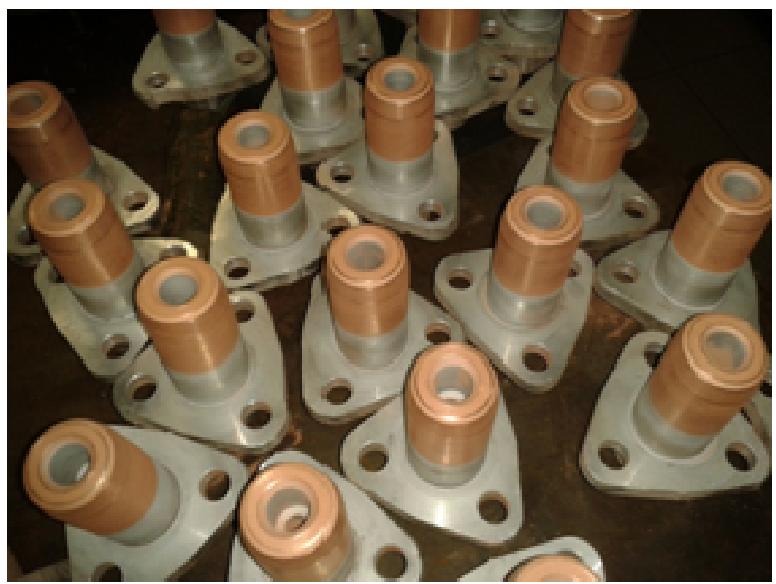

Figure 3. Contact part after an application of copper sublayer by detonation method

An application of coating was carried out in the following sequence: purging of nozzle of detonation equipment by air; filling of nozzle of detonation equipment with an explosive mixture of acetylene and oxygen; introduction of a portion of deposited powdered material (copper powder with dispersion of 40-60 micron) into nozzle; initiation of gas mixture by spark discharge; deposition of PM on a surface of aluminum contact; purge nozzle of an equipment after a projection by air (nitrogen); rotation of a workpiece on a handling device.

The required thickness (60-70 micron) was increased by a series of projections, during which workpiece and detonation equipment were moved by means of handling device (Figure 3).

One of requirements for a surface of electrical contact elements (ECE) with silver coating is wear resistance. As a technology of silver layer application electrochemical method of silver plating on non-cyanic electrolyte with use of asymmetric current of sinusoidal form was implemented (Shul'gin, 1974). That allows to obtain coatings with a gradient of strength and provides a required wear resistance. Analysis of various works in that direction (Bibikov, 1961; Burkat, 1984; Kochergin, \& Leont'ev, 1974; Ozerov, et al., 1972), allows to state the following benefits of metals electroplating with use of asymmetric alternating current: possibility of coatings' application in cold temperatures; increase of electrolysis speed and, consequently, productivity; capability of a wide interval change of physical and chemical properties of electroplating coatings; obtainment of denser and more finely grained coatings; increase of upper limit of working current density; decrease of internal stresses in coatings and others.

Mechanism of an intensification of electrochemical processes with asymmetric alternating current is related with a concentration of cations in a layer adjacent to cathode due to a periodic anodic dissolution, which allows to increase upper limit of working current density. A.I. Ionkin (Ionkin, et al., 1970) showed, that alternating current electric field causes "stripping" of hydrate shell of cations, which contributes to their discharge during cathode half-cycle. In the study (Klimnik, et al., 2008) the following explanation of processes taking place on asymmetric alternating current is presented. During cathode half-cycle grains growth in accordance with regular conditions of electroplating takes place. During anode half-cycle a partial dilution grains occurs, at that, the most protruding parts are dissolved in the first place (with the highest concentration force lines), including dendrites, which allows electroplating to be conducted in thin layers, and coating becomes smoother. Thus, electricity spent on dilution of coating is compensated by: 1) possibility to use higher current densities; 2) improved structure and properties of coating; 3 ) increase of scattering power.

A large number of technological parameters in deposition of coatings on asymmetric alternating current (asymmetry parameter, frequency, current density) make their optimization an important task. On the basis of a study of an influence of different frequency on behavior of ions during the work (Didenko, et al., 1988) for each element an existence of "resonance frequencies", in which best results are produced, is demonstrated.

$$
f=\frac{K}{n A}
$$

Where $\mathbf{f}$ - "resonance" frequency of asymmetric alternating current, $\mathrm{Hz} ; \mathbf{n}$ - valence of deposited element; $\mathbf{A}$ atomic weight of deposited element; $\mathbf{K}$ - limiting resonance frequency level (or ionization limiting level), which equals to $95519 \mathrm{~Hz}$. In accordance with that formula, time of ion contact with a surface (oscillation period) for 
his discharge is proportional to valency and atomic weight of element.

For a practical realization of coating's electroplating on an asymmetric alternating current different methods and devices are used (Sonin, et al., 2004; Sonin, et al., 2004). One of the simplest methods to receive asymmetric alternating current is to superimpose alternating current on current half-way rectification. Another way to change asymmetry parameter (ratio of current amplitudes of cathode and anode half-waves) is achieved by a dissipation of a part of anode half-way energy on an adjustable resistor. A disadvantage of such sources is unnecessarily high electricity consumption.

A disadvantage of both engineering solution for a creation of a source of asymmetric alternating current is an impossibility to control its frequency, while frequency, along with current density, determines number and quality of atomic layers, deposited during cathode half-wave. Moreover, currently there are now industrial sources of asymmetric alternating current, which makes a problem of a creation of modern automated manufacturing equipment for galvanic production quite topical.

Because of that, for a deposition of silver-diamond coatings, automated galvanic equipment was developed, for an application of electrochemical coatings using asymmetric alternating current, which allows to create coatings with a positive gradient of mechanical properties. Previously, for an obtainment of asymmetric alternating current of commercial frequency a transformer circuit with allocation of lower and higher half-waves with opposite diodes was used. Output voltage of the circuit is regulated by number of windings. For a realization of used method, an impulse source of current was developed, that allow to set up any shape of current. At the same time, the simplest form of current is harmonic oscillation with nonzero constant component. However, in a case of transition of transformer circuit to impulse source of current, a problem of a search for equivalent parameters of current shape appears. Without taking into account potential difference on electrodes, caused by nonzero concentration of oxidizer and reducer near surface of electrodes, the problem is formulated as follows. Current, formed by an impulse source, is harmonic oscillation, and it is defined by the equation:

$$
f(t)=A_{0} \sin \omega_{0} t+B_{0} ;
$$

where $\boldsymbol{A}_{\boldsymbol{0}}$ - current amplitude, $\boldsymbol{\omega}_{\boldsymbol{0}}=2 \pi \boldsymbol{f}_{0}-$ circular frequency, $\boldsymbol{t}$ - time, $\boldsymbol{B}_{\boldsymbol{0}}-$ constant component.

Transformers form voltage, which is defined separately by higher and lower half-waves. The equation, defining higher half-wave:

$$
f_{1}(t)=A_{1} \sin \omega_{0} t
$$

with $f_{l}(t) \geq 0$, which is satisfied in the interval $t \in\left[0 ; T_{0} / 2\right]$.

The equation, defining lower half-wave:

$$
f_{2}(t)=A_{2} \sin \omega_{0} t
$$

with $f_{2}(t) \geq 0$, which is satisfied in the interval $t \in\left[T_{0} / 2 ; T_{0}\right]$.

Resulting current is defined by the equation:

$$
g(t)=f_{1}(t)+f_{2}(t) .
$$

It is obvious, that quantity of charge flowing in a period, and, therefore, mass of transported matter to a surface of electrode from a solution and taking off of a product from a reaction zone in a case of non equal amplitudes of oscillations $f(t)$ and $g(t)$ are not equivalent. Amplitude and constant component of that harmonic oscillation is defiened by the equation:

$$
\left\{\begin{array} { l } 
{ A _ { 0 } + B _ { 0 } = A _ { 1 } ; } \\
{ A _ { 0 } - B _ { 0 } = A _ { 2 } ; }
\end{array} \Rightarrow \left\{\begin{array}{l}
A_{0}=\left(A_{1}+A_{2}\right) / 2 ; \\
B_{0}=\left(A_{1}-A_{2}\right) / 2 ;
\end{array}\right.\right.
$$

For a formation of coating of a required thickness, both methods of current formation must guarantee equal charge, flowing in a period $\boldsymbol{T}_{\boldsymbol{0}}$, inthe interval $\left[0 ; \boldsymbol{T}_{\boldsymbol{0}}\right]$ and, therefore, in intervals $\left[0 ; \boldsymbol{T}_{0} / 2\right],\left[\mathbf{0} ; \boldsymbol{t}_{\boldsymbol{1}}\right]$ and in intervals $\left[\boldsymbol{T}_{0} / 2 ; \boldsymbol{T}_{0}\right],\left[\boldsymbol{t}_{1}, \boldsymbol{T}_{0}\right]$, where $\boldsymbol{t}_{1}-$ root of the equation $f(t)=0$.

$$
\int_{0}^{t_{1}} f(t) d t=\int_{0}^{T_{0} / 2} f_{1}(t) d t
$$




$$
\int_{t_{1}}^{T_{0}} f(t) d t=\int_{T_{0} / 2}^{T_{0}} f_{2}(t) d t
$$

From (5) (higher half-wave), follows $\int_{0}^{t_{1}}\left(A_{0} \sin \omega_{0} t+B_{0}\right) d t=\int_{0}^{T_{0} / 2}\left(A_{1} \sin \omega_{0} t\right) d t$

$$
\left(-\frac{A_{0}}{\omega_{0}} \cos \left(\omega_{0} t\right)+B_{0} t\right)_{0}^{t_{1}}=\left(-\frac{A_{1}}{\omega_{0}} \cos \left(\omega_{0} t\right)\right)_{0}^{T_{0} / 2}=>B_{0} t_{1}-\frac{A_{0}}{\omega_{0}} \cos \left(\omega_{0} t_{02}\right)+\frac{A_{0}}{\omega_{0}}=\frac{A_{1}}{\omega_{0}}-\frac{A_{1}}{\omega_{0}} \cos \left(\omega_{0} T_{0} / 2\right)
$$

because $\omega_{0} T_{0} / 2=2 \pi f_{0} *\left(1 / 2 f_{0}\right)=\pi$, then $\cos \left(\omega_{0} T_{0} / 2\right)=\cos (\pi)=-1$, therefore,

$$
B_{0} t_{1}-\frac{A_{0}}{\omega_{0}} \cos \left(\omega_{0} t_{1}\right)+\frac{A_{0}}{\omega_{0}}=2 \frac{A_{1}}{\omega_{0}}
$$

From (2) (lower half-wave), follows

$$
\begin{gathered}
\int_{t_{1}}^{T_{0}} f(t) d t=\int_{T_{0} / 2}^{T_{0}} f_{2}(t) d t \Rightarrow \int_{t_{1}}^{T_{0}}\left(A_{0} \sin \omega_{0} t+B_{0}\right) d t=\int_{T_{0} / 2}^{T_{0}}\left(A_{2} \sin \omega_{0} t\right) d t \\
\left(-\frac{A_{0}}{\omega_{0}} \cos \left(\omega_{0} t\right)+B_{0} t\right)_{t 1}^{T_{0}}=\left(-\frac{A_{2}}{\omega_{0}} \cos \left(\omega_{0} t\right)\right)_{T_{0} / 2}^{T_{0}} \Rightarrow B_{0} T_{0}-B_{0} t_{1}+\frac{A_{0}}{\omega_{0}}\left(\cos \left(\omega_{0} t_{1}\right)-1\right)=-2 \frac{A_{2}}{\omega_{0}}
\end{gathered}
$$

By excluding $\boldsymbol{t}_{\boldsymbol{l}}$ finally obtaining system of two equations relatively to two unknown parameters $\boldsymbol{A}_{\boldsymbol{0}}, \boldsymbol{B}_{0}$ :

$$
\left\{\begin{array}{l}
B_{0} \arcsin \left(-\frac{B_{0}}{A_{0}}\right)-A_{0}\left(\sqrt{1-\left(-\frac{B_{0}}{A_{0}}\right)^{2}}-1\right)=2 A_{1} \\
B_{0}=\left(A_{1}-A_{2}\right) / \pi
\end{array}\right.
$$

Thus, by solving (9), obtaining parameters of harmonic signal of manufacturing current, which guarantees equivalent conditions in speed and quality of coatings deposition on two different forms of current. Three different forms of current are presented in figure 4. First is asymmetric shape of current, provided by transformer source, second is harmonic oscillation, which parameters are defined by (2), third is is harmonic oscillation, which parameters are defined by (9). 


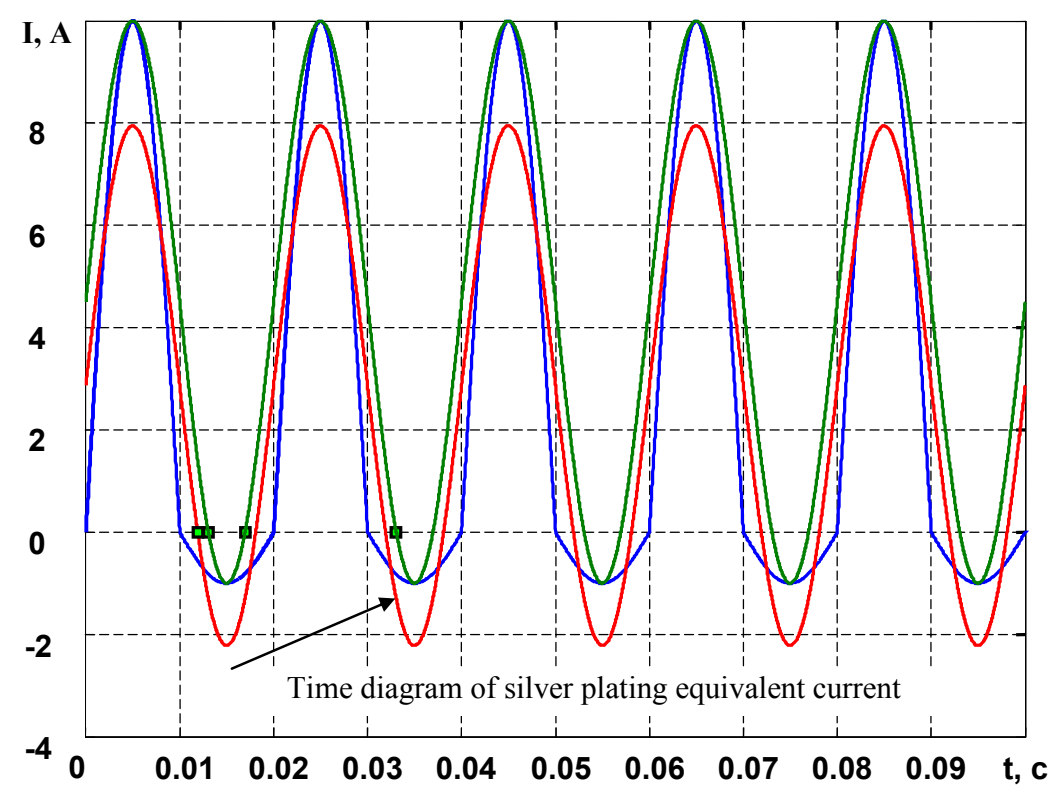

Figure 4. Time current diagrams of silver plating, formed by an impulse controlled current source and transformer source, brought to one point

An equipment, which is developed on a basis of programmable controller with a built-in microprocessor, allows to automatically control electrolysis using specified program with a feature that allow to freely select type of current (direct, alternating, impulse, asymmetric, etc.), a selection of value and duration of pulses direct and reverse currents, a pause between them, positive or negative offset of permanent part of current, provision of a stabilization of current and voltage (Figure 5).

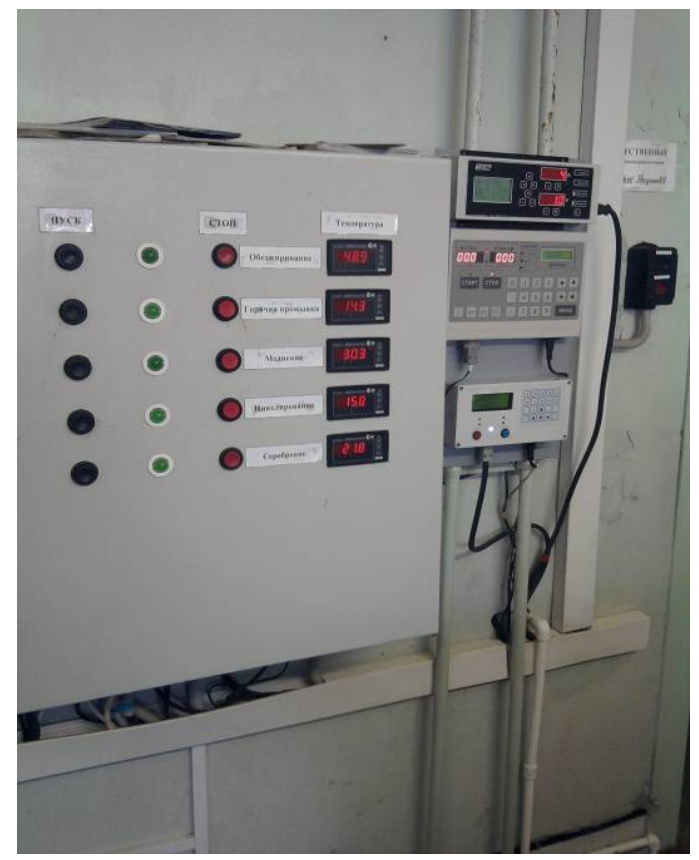

Figure 5. Equipment for nanostructured silver-diamond coatings' deposition

A distinctive feature of the equipment is an ability to generate pulses with varying steepness of pulse edge and varying frequency of asymmetric AC with adjustable asymmetry coefficient. Programming of equipment is possible both from a control console and directly from a computer. The program keeps a record and a record of generated diagrams of current parameters of electrolysis (current and voltage at output of a source, voltage on 
electrodes in a manufacturing bath, electrolyte temperature, specific conductivity of electrolyte) throughout a process of coating application. (Galliyamov, \& Ibatullin, 2014).

In a process of coating application a pre-programed sequence of technological regimes of coatings' deposition is conducted, in which each subsequent regime generates coating with less harness. That allows to obtain a favorable positive gradient of mechanical properties in coatings, whiha are designed to improve service life if friction units of machines. The equipment allows to create high-quality coatings on parts of machines with a possibility for an optimization and saving of selected sequences of technological regimes for an application of coatings on sets of parts of various configurations.

One of promising ways of an increase of quality of protective coatings' is a co-deposition superdispersed diamonds (SDD) with metals during their chemical or electrochemical reduction from aqueous solutions. Used SDD are particles which shape is close to spherical or oblong. In the present time they are increasingly defined as "nanodiamonds". Each particle of nanodiamond is composed of a variety of individual diamond crystals with size of $5 \ldots 7 \mathrm{~nm}$. Those particles may form stable, in contexts of sedimentation and coagulation, systems in electrolytes. At that, SDD possess properties, which combine properties of one of the hardest substances in nature with chemically active shell in a form of functional groups that are capable, to participate in chemical and electrochemical processes (Ganigin et al., 2010). The results of studies showed, that metal-diamond coatings have following characteristics: increase of wear resistance and microhardness; significant increase of corrosion resistance and decrease of porosity; increase of antifriction performance of surface; significant increase of cohesion and adhesion; high scattering power of electrolytes. SSD introduced in electrolyte possess high absorption properties (from 1 to $10 \mu \mathrm{g}$-eqv. $/ \mathrm{m}^{2}$ ) and bind acid and basic metallic remains, which increase cathodic polarization and, thus, facilitates a creation of fine-crystalline precipitations. It allows nanodiamond particle to absorb from tens to many hundreds of milligrams of ionized metal on $1 \mathrm{~g}$ of SDD and take part in a transport of metallic ions to a surface of cathode. For example, each gram of SDD combines and transports from 20 to $380 \mathrm{mg}$ of silver. Depostino of coatings from SSD-containing electrolytes allows rapidly decreasing dendrite formation and at the same time operating with higher current densities (Ganigin, et al., 2011).

\section{Results}

A comparative analysis of silver coatings properties, which are produced with a new technology, with coatings from alloys "silver-antimony (2\%)" and "silver-nickel (5\%)", shown that silver-diamond coating with less hardness (HV is $60 \ldots 80 \mathrm{kgf} / \mathrm{mm}^{2}$ ) is $1.5 \ldots 2$ times exceeds durability of traditional silver coatings with antimony and has a smaller coefficient of friction. Sclerometrictests shown that programs developed for coating have higher plasticity reserve - accumulated energy in a case of fracture exceeds that for regualr coatings to $53 \%$. That fact indicates that functional properties antiscuff antifriction coatings are determined by plasticity, rather than hardness.

For a study of adhesion, weer-resistance and electrical properties of developed coatings, experimental-industrial test on a group of electric contacts were conducted. Tests were carried out on a basis of laboratory of "Gruppa companii "Electroshit" - TM Samara" CJSC. Coatings were deposited on aluminum riveted contacts SESha-70 with $36 \mathrm{~mm}$ diameter. Mechanical wear-resistance tests were conducted according to mehtodology complying with OGK-KRU-SESha-70, according to that methodology, on each specimen 2000 of connection-disconnection cycles of contact parts were conducted, with a control of pulling force, electrical resistances and quality of the surface of coatings every 250 cycles. An average value of pulling force of aluminum contact parts with silver-diamond coating was $9 \mathrm{kgf}$ and $9.5 \mathrm{kgf}$ for copper contact with regular silver coating, at the same time, an average value of electrical resistance of contact parts was 7.8 microhm with acceptable value of 14 microhm.

In order to evaluate protection properties of silver-diamond coating corrosion resistance tests of lamels were conducted. Corrosion test were carried out according to GOST9.308-85 (ST SEV 3627-82, ST SEV 3628-82, ST SEV 3629-82) in salt spray chamber with $(35 \pm 2){ }^{\circ} \mathrm{C}$ temperature and use of sodium chlorine with $(50 \pm 5) \mathrm{g} / \mathrm{dm} 3$ concentration. Total tests time as 96 hours. Experiments demonstrated, that sufficient for operation requirements protective properties are achieve with thickness of silver-diamond coatings $\geq 20$ micron.

Also, combined functional coatings of copper-silver type on electric contacts were subjected to joint tests with regular copper analogues (KRU SESha ${ }^{\circledR}-70-10-1000 / 20$ UZ according to TU 3414-092-15356352-2007). Main characteristics of KRU SESha ${ }^{\circledR}-70-10-1000 / 20$ UZ: Rated voltage, $10 \mathrm{kV}$, Rated current, $1000 \mathrm{~A}$, Rated breaking current, $20 \mathrm{kA}$, Environment rating - U (moderate climate),Placement rating - 3 (inside building without climate control). The aim of the test is to verify compliance of combined and regular specimens of ECE with GOST8024-90 R.1 Tests were carried out according to GOST 8024-90 R 2.Prior to electrical current heating test, KRU SESha ${ }^{\circledR}-70-10-1000$ UZ with contact part (two aluminum buses, connected by welding with 
aluminum contact) and test with vacuum switch VV/TEL-10-20/1000 U2, electrical resistance of main circuits was measured. Results of heating tests of KRU SESha ${ }^{\circledR}-70-10-1000$ UZ with contact part by current I=1000 A are presented in table 2 .

Table 2. Results of electric current heating test

\begin{tabular}{cccc}
\hline $\begin{array}{c}\text { Name of parts of equipment, } \\
\text { materials (coatings) }\end{array}$ & $\begin{array}{c}\text { Temperature of control points heating, } \\
\text { brought to effective value of temperature } \\
\text { of surrounding air } 40{ }^{\circ} \mathrm{C}\end{array}$ & $\begin{array}{c}\text { The highest } \\
\text { allowable } \\
\text { temperature } \\
\text { according to GOST } \\
8024-90\end{array}$ & $\begin{array}{c}\text { Comply } \\
\text { GOST } \\
8024-90\end{array}$ \\
\hline Connection, copper/aluminum & & 90 & Comply \\
Connection, aluminum & $79.7 /$ Touch field $81.0 / 79.1$ & 120 & Comply \\
Contact, copper (silver) & $82.0 / 81.9 / 79.5$ & 120 & Comply \\
Contact, copper (silver) & $91.3 / 93.2 / 90.5$ & 120 & Comply \\
\hline
\end{tabular}

\section{Conclusion}

Was developed a new perspective manufacturing techniques of multilayered coverings on electric contacts, with possibility of replacement of a material of a basis - copper on cheaper - aluminium. The carried out analysis of existing technologies of drawing of an intermediate intermediate layer of copper, has revealed economic and technological efficiency of application of technology of detonation drawing of coverings. The innovative technology and the process equipment was developed for applying gradient on hardness of silver-diamond coverings with application nanostructural additives of ultradisperse diamonds. It is established, that an application of coatings, deposited using the developed technology allows to decrease labor-intensiveness and costs of produced electrical contacts in (1.5...2) times, while retaining wear resistance and electrical properties of electrical equipment, operating in conditions of high mechanical and current loads. Currently, the technology and manufacturing equipment for a deposition of wear-resistant silver-diamond coatings on aluminum contacts are undergoing implementation into mass production in cooperation with "GK Elektroshit" CJSC, demonstrating high efficiency in a course of experimental-industrial and operating tests.

\section{Acknowledgments}

The study has been carried out with the financial support of the Ministry of Education and Science of Russian Federation on the basis of grant (RFMEFI57414X0010) No. 14.574.21.0010 from 06.17.2014 (Sonin, et al., 2004; Sonin, et al., 2004).

\section{References}

Lukomski, Yu., \& Gorshkov, V. (1985). Galvanic coatings and paints on aluminum and its alloys. Leningrad: Chemistry.

Hasui, A. (1988). Technique of deposition. Moscow: Metallurgy.

Sova, A., et al. (2009). Comparison of Cold Spray and Detonation Coatings Properties. Retrieved October 25, 2014, from http://dnb.ddb.de

Barten'ev, S., et al. (1982). Detonation coatings in machine-building industry. Leningrad: Mechanical Engineering.

Yu., A., et al. (2003). Gas Detonation and its Application in Engineering and Technologies. Combustion, Explosion, and Shock Waves., 4(39), 382-410.

Gavrilenko, T., et al. (2006). Automated detonation complex "Ob"' for an application of powder coatings. Modern automation technologies, 47-52.

Ul'yanicki, V., et al. (2010). Experience in research and application of detonation coatings. Bulletin Samara scientific center of RAS, 569-575.

Kadyrov, V., \& Ladan, E. (2002). Gas-detonating units "ADM" for a deposition. Welder, 3(25), 13-14.

Kadyrov, V., et al. (1996). Detonation spraying coating: properties and applications. $10^{\text {th }}$ International Conference on Surface modification Technologies.

Shul'gin, L. (1974). Electrochemical processes at alternating current. Moscow: Nauka. 
Bibikov, N. (1961). Metal deposition on the current of variable polarity. State scientific and technical publishing house of mechanical engineering literature.

Burkat, G. (1984). Methods of application of silver, gold, palladium and rhodium. Leningrad: Mechanical engineering.

Kochergin, S., \& Leont'ev, A. (1974). Formation of textures during electrocrystallization of metals. Moscow: Metallurgy.

Ozerov, A., et al. (1972). Non-stationary electrolysis. Nizhne-Volzhskoe publishing house.

Ionkin, A., Karakaev, V., \& Koshekev, A., et al. (1970). Research in the field of applied galvanochemistry. Works of Novocherkassk polytechnic institute of S.Ordzhonikidze name.

Kilimnik, A., et al. (2008). Scientific foundations of ecologically friendly electrochemical processes of organic compounds' synthesis on alternating current: Monograph. Tambov: Publishing house of Tambov State Technical University.

Didenko, A., et al. (1988). Intensification of electrchemical processes using assymetric alternating current. Intensification of electrochemical processes, 189-214.

Sonin, A., et al. (2004). Influence of electrolysis regime on a deposition of silver from pyrophosphatic electrolyte. News of Higher Education Institutions. Chemistry and Chemical Engineering, 47, 57-59.

Sonin, A., et al. (2004). Peculiaritires of distribution of silver in different modes of electroplating from polyligand electrolyte. News of Higher Education Institutions. Chemistry and Chemical Engineering, 47, 53-55.

Galliyamov, A., \& Ibatullin, I. (2014). New technology, properties and application of nanostructured antifriction electrochemical coatings. Life Science Journal, 11(12s), 586-591.

Ganigin, S., et al. (2010). Use of nanostructured coatings in gliding support of drill bits. Bulletin of Samara scientific center of RAS, 1, 357-361.

Ganigin, S., et al. (2011). Prospective technologies, properties and application of nanostructured electrochemical coatings. Journal of Samara State Aerospace University named after academician S.P. Korolev, 3, 189-196.

\section{Copyrights}

Copyright for this article is retained by the author(s), with first publication rights granted to the journal.

This is an open-access article distributed under the terms and conditions of the Creative Commons Attribution license (http://creativecommons.org/licenses/by/3.0/). 